\title{
ÍNDICES DE INFESTAÇÃO DE LARVAS E NINFAS DE RHIPICEPHALUS SANGUINEUS EM PRAÇAS PÚBLICAS DE ARAÇATUBA-SP
}

\author{
Letícia Vinhas Rampim ${ }^{1}$
}

\section{Tamilis Cornachini $^{2}$}

\section{Luiz Gustavo Ferraz Lima ${ }^{3}$}

RESUMO: Rhipicephalus sanguineus é um ectoparasito de cães e gatos, mas também ocorre em humanos. Por ser hematófago, transmite doenças graves, podendo levar os hospedeiros a morte. As praças públicas são utilizadas por pessoas, mas também frequentemente por cães e outros animais. Nesses lugares, os carrapatos podem descer dos animais, colocar seus ovos no ambiente e posteriormente infestar novos hospedeiros. Esse estudo teve como objetivo avaliar os níveis de infestação por larvas, ninfas e adultos de R. sanguineus, em duas praças públicas de Araçatuba e correlacioná-los às condições climáticas. As coletas foram feitas semanalmente, de agosto de 2012 a junho de 2013, por meio da técnica de arrasto, para obtenção de carrapatos. A identificação do estágio de vida foi por meio de um microscópio estereoscópico, com aumento de 40x. Na Praça 1, em 16 coletas foram capturados 48 carrapatos, todos em fase de larva. $\mathrm{Na}$ Praça 2, em 19 coletas foram capturados 40 carrapatos, dos quais 39 larvas e uma ninfa. Durante o estudo foi registrado $22,4^{\circ} \mathrm{C}$ de temperatura média ambiental. Não foi possível a identificação das larvas e ninfas, uma vez que as chaves dicotômicas se restringem a forma adulta, não obtida nesse estudo. Não houve diferença estatística entre o número de carrapatos encontrados nas praças 1 e 2, e também não houve correlação entre o número de carrapatos, com a temperatura e a chuva. Infestações por larvas de carrapatos foram constatados nas praças em estudo.

Palavras chave: Carrapato. Infestação. Praças.

${ }_{1}^{1}$ Graduanda em Ciências Biológicas, Centro Universitário Católico Auxilium. letvinhas@gmail.com.

${ }^{2}$ Graduanda em Medicina Veterinária, Centro Universitário Católico Auxilium. tacornachini@gmail.com.

${ }^{3}$ Biólogo, Universidade Estadual Júlio Mesquita Filho. gustalima@hotmail.com. 


\section{INTRODUÇÃO}

Rhipicephalus sanguineus é uma espécie conhecida como carrapato vermelho do cão, cosmopolita, tendo sido introduzida no continente americano juntamente com os cães. Acredita tratar-se de uma espécie originalmente africana. A sua preferência por cães como hospedeiro facilitou sua disseminação pelo globo. Este é um artrópode da subclasse Acari e família Ixodidae, alimentam-se em cada fase sobre um novo hospedeiro, voltando ao solo sempre que completam sua refeição sanguínea. Cada $R$. Sanguineus suga, portanto três hospedeiros (FERNANDES, 2000)

Quatro a cinco dias depois de alimentarem-se, as fêmeas oviporam de $1.000 \mathrm{a}$ 3.000 ovos, colocados em duas semanas e eclodindo em três semanas a $25^{\circ} \mathrm{C}$. Depois de quatro ou cinco dias, as larvas instalam-se no seu primeiro hospedeiro. O ciclo começa em dois ou três meses, porém em regiões temperadas pode haver hibernação. A longevidade dos adultos é de aproximadamente um ano, prolongando-se em regiões frias (REY, 2008)

Em jejum apresenta corpo achatado dorsoventralmente. Por serem revestidos por um tegumento coriáceo e distensível, podem aumentar de volume, quando ingerido sangue. Os adultos possuem quatro pares de pernas, enquanto as larvas possuem somente três pares.

Os $R$. Sanguineus, quando vão alimentar-se, caminham sobre a pele do hospedeiro, tocando-as com as extremidades dos palpos, onde se encontram estruturas sensoriais. Para introduzir seu hopostômio, as quelíceras funcionam como órgão cortante, graças ao movimento de deus dígitos que dilaceram a pele e também penetram. $O$ hopostômio possui fileiras de dentes quitinosos e atua como órgão de fixação (FORTES, 2004). No cão as formas imaturas fixam-se no pescoço do animal, os adultos frequentemente se localizam na parte interna do pavilhão auricular e entre os dedos. Mas todas as fases podem ser encontradas em qualquer parte do corpo. (SERRA-FREIRA E MELHO, 2006)

As altas infestações provocam desde leves irritações até anemia por ação espoliadora. Esse artrópode, por exercer hematofagia, é um importante vetor biológico 
e reservatório de Ehrlichia canis, sendo responsável também pela transmissão de outros patógenos como babesiose canina, Rangelia vitale e da riquetisiose canina (SEXTON ET AL., 1976). O carrapato também pode transmitir os bioagentes da babesiose equina, da anaplasmose para bovinos e Rickettsia rickettsii, bioagente da febre maculosa. (SERRA-FREIRE E MELHO, 2006)

As larvas não ingerem apenas sangue, líquido intersticial também é ingerido. Contudo o $R$. Sanguineus é capaz de suportar jejum prolongado que podem durar vários meses. Dependendo da temperatura e de outras condições do meio, a eclosão dos ovos pode dar-se em 40 dias. A larva alimenta-se e cresce até sofrer sua primeira muda, do que resultara uma ninfa.

No Brasil, durante uma investigação sobre as espécies de ectoparasitas de cães domésticos provenientes da Região Metropolitana de Recife, Pernambuco, quatro proprietários de cães foram encontrados parasitados por carrapatos. Foram coletados carrapatos dos indivíduos e de seus cães e todos os carrapatos foram identificados como R. sanguineus (Dantas-Torres et al., 2006).

Os fatores ambientais podem influenciar a prevalência do carrapato em hospedeiros. No México, verificou-se que as infestações nas estações da primavera, outono e verão foram $20 \%$ maiores que no inverno (CRUZ-VASQUEZ E GARCIAVASQUEZ, 1998). Apesar de sua importância no Brasil, os dados sobre a sazonalidade de $R$. sanguineus são limitadas, especialmente em relação à infestação natural de cães. Em Belo Horizonte-MG, entre os cães que vivem em casas, foram observados picos de população de carrapatos em agosto, fevereiro e junho, com temperatura média de 18,6 ${ }^{\circ} \mathrm{C}$, umidade relativa do ar de $56,5 \%$ e precipitação pluviométrica de $37 \mathrm{~mm}$, durante o período de estudo (SILVEIRA ET AL., 2009).

A profilaxia necessária para Rhipicephalus sanguineus é banhar o animal com carrapaticida, pulverizar carrapaticida na cama, paredes e chão do canil e proceder à inspeção semanal dos animais para comprovar a presença ou não do carrapato. (Fortes, 2004).

Nos últimos anos tem ocorrido um aumento considerável de infestação em cães e o problema tem se agravado ano após ano, com queixas da população de invasão de residências pelo carrapato e até de casos de parasitismo em humanos (sobretudo crianças), o que representa um risco à saúde pública. $\mathrm{O}$ desconhecimento sobre o 
comportamento do ixodídeo na região e seus parâmetros biológicos, dificulta ainda mais qualquer tentativa de controle feita pelos órgãos responsáveis.

Dessa forma, o objetivo do presente trabalho foi avaliar os índices de infestação de larvas e ninfas de Rhipicephalus sanguineus em praças públicas de Araçatuba, interior de São Paulo, e avaliar a influência da temperatura ambiente, umidade relativa do ar e dos valores pluviométricos sobre os índices de infestação ambiental.

\section{DESENVOLVIMENTO}

Os índices de infestação ambiental por $R$. sanguineus, nos locais públicos, onde os cães costumam freqüentar, permitiu obter maiores informações sobre a dinâmica de infestação e da transmissão de parasitoses que acometem os cães, obter maiores informações para a escassa literatura referente ao tema e sobretudo campanhas de saúde que visem o controle das infestações ambientais, infecções dos animais e eventuais problemas de saúde animal.

O trabalho foi desenvolvido em duas praças públicas, Praça Getúlio Vargas e Praça João Pessoa, no município de Araçatuba, localizado a 528 km da capital paulista, São Paulo, Brasil, a 50ํ6' longitude Oeste e 21ำ12' latitude Sul, e $398 \mathrm{~m}$ de altitude.

De agosto de 2012 e junho de 2013, entre 14:00 e 18:00 horas foram utilizadas em praças públicas a técnica de arrasto para obtenção de amostras de larvas, ninfas e formas adultas de carrapatos, semanalmente, durante o período do projeto.

A técnica de arrasto consiste na utilização de uma flanela branca com dimensões de 1,50m de comprimento por 0,80m de largura, com duas hastes de ferro (vergalhão), de canos de ferro, de 0,85m e meia polegada de diâmetro, transpassadas em presilhas feitas em cada extremidade da mesma, com o objetivo de manter a flanela aberta e o mais próximo possível do chão e se necessário fixar pesos um quilo e meio no total na extremidade posterior (OLIVEIRA, 1998). A técnica de arrasto é indicada tanto para locais com vegetação do tipo herbácea (gramíneas, leguminosas, compostas e outras forrageiras), como para áreas de confinamento de animais (pastos) ou domicílio. Foi percorrido os canteiros gramados da praças. $O$ arrasto foi executado, andando lentamente e parando a cada 4 a 5 metros, para verificação e coleta de indivíduos capturados sobre a face da flanela arrastada em contato com a superfície. 


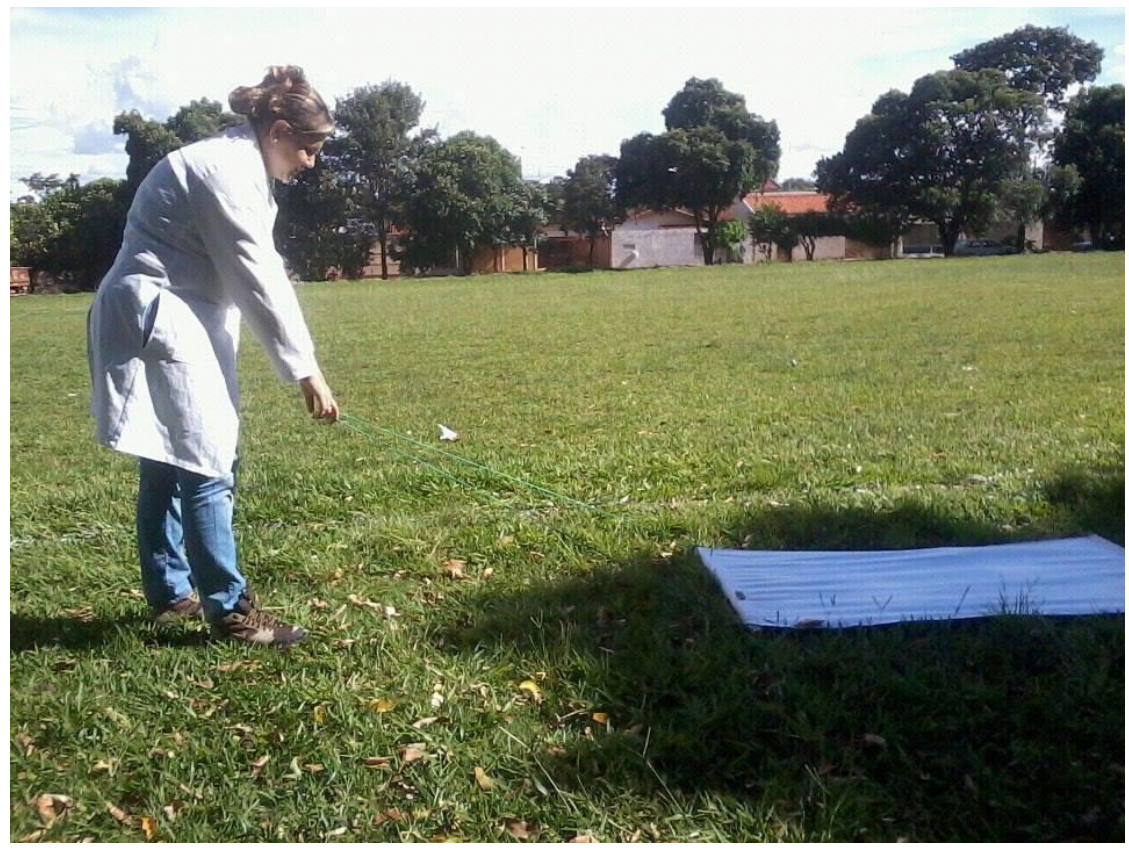

Figura 1: Técnica de Arrasto

Os carrapatos coletados nas praças foram acondicionados em frascos de plástico e conservados com solução alcoólica $70 \%$. Cada frasco foi devidamente identificado com o número da amostra e a data da coleta.

Para a identificação do estágio de vida (larva ou ninfa) dos carrapatos, foi utilizado um microscópio estereoscópico (lupa), com iluminação incidente. A identificação dos gêneros de larvas e ninfas não foi possível, pois as chaves dicotômicas disponíveis na literatura são restritas ao estágio adulto desses gêneros.

Os dados diários de temperatura ambiental, umidade relativa do ar e do índice pluviométrico foram obtidos na Coordenadoria de Assistência Técnica Integral - CATI, de Araçatuba-SP.

Foi realizada análise descritiva com cálculos do número total, porcentagem, número médio de larvas, ninfas e adultos $(\overline{\mathbf{x}})$ coletados nas praças.

Para a análise estatística, foi aplicado o teste de Mann-Whitney e de Spearman, considerando variâncias heterogêneas e para análise de correlação entre temperatura e porcentagem de carrapatos encontrados.

$\mathrm{Na}$ Praça Getúlio Vargas (Tabela 1) em 16 coletas foram capturados 48 carrapatos, todos em fase de larva. Na Praça João Pessoa (Tabelo 2), em 19 coletas foram capturados 40 carrapatos, dos quais 39 eram larvas e uma ninfa. A maior coleta foi de nove (9) carrapatos na Praça 1 , e de seis (6) na praça 2 , a $22,4^{\circ} \mathrm{C}$ e $28,3^{\circ} \mathrm{C}$ de 
temperatura média ambiental, respectivamente.

\begin{tabular}{cccc}
\hline Amostras & Larvas & Ninfas & Adultos \\
\hline $29 / 10 / 2012$ & 2 & 0 & 0 \\
$10 / 12 / 2012$ & 4 & 0 & 0 \\
$17 / 12 / 2012$ & 4 & 0 & 0 \\
$31 / 12 / 2012$ & 1 & 0 & 0 \\
$07 / 01 / 2012$ & 2 & 0 & 0 \\
$14 / 01 / 2013$ & 6 & 0 & 0 \\
$21 / 01 / 2013$ & 1 & 0 & 0 \\
$04 / 02 / 2013$ & 3 & 0 & 0 \\
$25 / 02 / 2013$ & 1 & 0 & 0 \\
$11 / 03 / 2013$ & 3 & 0 & 0 \\
$18 / 03 / 2013$ & 3 & 0 & 0 \\
$25 / 03 / 2013$ & 1 & 0 & 0 \\
$01 / 04 / 2013$ & 1 & 0 & 0 \\
$08 / 04 / 2013$ & 3 & 0 & 0 \\
$15 / 04 / 2013$ & 4 & 0 & 0 \\
$22 / 04 / 2013$ & 9 & 0 & 0 \\
\hline total & 48 & 0 & 0
\end{tabular}

média

$3 \quad 0 \quad 0$

Tabela 1: Périodo, número de larvas, ninfas e adultos de carrapatos coletados do período de agosto de 2012 a abril de 2013, na praça pública Getúlio Vargas, Araçatuba-SP.

\begin{tabular}{cccc}
\hline Amostras & Larvas & Ninfas & Adultos \\
\hline $05 / 11 / 2012$ & 0 & 1 & 0 \\
$10 / 12 / 2012$ & 6 & 0 & 0 \\
$17 / 12 / 2012$ & 4 & 0 & 0 \\
$31 / 12 / 2012$ & 1 & 0 & 0 \\
$07 / 01 / 2013$ & 2 & 0 & 0 \\
$14 / 01 / 2013$ & 1 & 0 & 0 \\
$21 / 01 / 2013$ & 4 & 0 & 0 \\
$28 / 01 / 2013$ & 2 & 0 & 0 \\
$04 / 02 / 2013$ & 2 & 0 & 0 \\
$11 / 02 / 2013$ & 1 & 0 & 0 \\
$18 / 02 / 2013$ & 3 & 0 & 0 \\
$25 / 02 / 2013$ & 1 & 0 & 0 \\
$04 / 03 / 2013$ & 2 & 0 & 0 \\
$11 / 03 / 2013$ & 1 & 0 & 0 \\
$18 / 03 / 2013$ & 1 & 0 & 0 \\
$01 / 04 / 2013$ & 1 & 0 & 0 \\
$08 / 04 / 2013$ & 1 & 0 & 0 \\
$15 / 04 / 2013$ & 3 & 0 & 0
\end{tabular}




\begin{tabular}{cccc}
$22 / 04 / 2013$ & 3 & 0 & 0 \\
\hline total & 39 & 1 & 0 \\
média & 2,1 & 0,0 & 0,0 \\
\hline
\end{tabular}

Tabela 2: Período, número de larvas, ninfas e adultos de carrapatos coletados do período de agosto de 2012 a abril de 2013, na praça pública João Pessoa, Araçatuba-SP.

A análise estatística de Mann-Whitney demonstrou que não houve diferença estatística $(p>0,05)$ ente o número de carrapatos encontrados nas praças 1 e 2 .

Os dados climáticos coletados na CATI mostraram temperatura média de 25,7ํㅡ (Tabela 3) e índice pluviométrico médio de 138,7mm (Tabela 4), durante a realização das coletas.

\begin{tabular}{ccc}
\hline Semana & $\begin{array}{c}\text { Temp. Mínima } \\
\text { (C) }\end{array}$ & $\begin{array}{c}\text { Temp. Máxima } \\
\text { (oC) }\end{array}$ \\
\hline $21 / 10 / 2012$ & 21,2 & 35,6 \\
$28 / 10 / 2012$ & 22,9 & 37,6 \\
$04 / 11 / 2012$ & 20,6 & 32,0 \\
$09 / 12 / 2012$ & 22,6 & 34,0 \\
$16 / 12 / 2012$ & 20,9 & 30,0 \\
$30 / 12 / 2012$ & 21,0 & 31,8 \\
$06 / 01 / 2013$ & 20,6 & 31,5 \\
$13 / 01 / 2013$ & 18,9 & 29,4 \\
$20 / 01 / 2013$ & 20,6 & 31,6 \\
$27 / 01 / 2013$ & 21,4 & 31,9 \\
$03 / 02 / 2013$ & 19,8 & 27,8 \\
$10 / 02 / 2013$ & 20,7 & 33,3 \\
$17 / 02 / 2013$ & 21,8 & 33,0 \\
$24 / 02 / 2013$ & 20,8 & 31,2 \\
$03 / 03 / 2013$ & 22,0 & 34,8 \\
$10 / 03 / 2013$ & 21,7 & 33,8 \\
$17 / 03 / 2012$ & 19,1 & 26,1 \\
$24 / 03 / 2012$ & 18,4 & 28,2 \\
$31 / 03 / 2013$ & 19,8 & 30,3 \\
$07 / 04 / 2013$ & 20,1 & 28,9 \\
$14 / 04 / 2013$ & 15,6 & 27,6 \\
$21 / 04 / 2013$ & 16,4 & 28,4 \\
\hline Média & $\mathbf{2 0 , 3}$ & $\mathbf{3 1 , 3}$ \\
\hline DP & $\mathbf{1 , 8}$ & $\mathbf{2 , 9}$ \\
\hline
\end{tabular}

Tabela 3: Temperatura mínima e máxima registrados em Araçatuba-SP durante o período de estudo.

\begin{tabular}{cc}
\hline Mês & Precipitação $(\mathbf{m m})$ \\
\hline set/12 & 138,60 \\
out $/ 12$ & 50,90
\end{tabular}




\begin{tabular}{cc} 
nov/12 & 160,10 \\
$\mathrm{dez} / 12$ & 164,30 \\
$\mathrm{jan} / 13$ & 148,30 \\
$\mathrm{fev} / 13$ & 157,70 \\
$\mathrm{mar} / 13$ & 230,40 \\
$\mathrm{abr} / 13$ & 59,80 \\
\hline Média & $\mathbf{1 3 8 , 7 6}$ \\
\hline DP & $\mathbf{5 8 , 4 4}$
\end{tabular}

Tabela 4: Precipitação registrada durante o período de estudo

No teste estatístico de Sperman, não houve correlação significativa entre o número de carrapatos, com a temperatura e a chuva.

\section{CONCLUSÃO}

Não foi possível a identificação das larvas e da ninfa, uma vez que as chaves dicotômicas se restringem a forma adulta, não obtida nesse estudo. Mas o resultado evidência alto número de carrapatos, sugerindo que as praças públicas podem servir como locais de infestação para os animais domésticos e seus cuidadores, uma vez que determinadas espécies podem parasitar diferentes hospedeiros.

A não correlação entre número de amostras, temperatura e índice pluviométrico constatados no trabalho entra em conflito com estudos sobre infestações em animais, onde são constatadas altas infestações em temperaturas mais quentes e índice pluviométrico maior, o que sugere que há uma permanência maior do carrapato no ambiente do que no hospedeiro.

\section{REFERÊNCIAS}

AGUIAR, Cíntia Lidiane Guidotti; PAPPEN, Felipe; PINTO, Diego Moscarelli; SANTOS, Luciana Siqueira Silveira dos; SANTOS, Tânia Regina Bettin dos; FARIAS, Nara Amélia da Rosa. ASPECTOS BIOLÓGICOS DE Rhipicephalus sanguineus (ACARI: IXODIDAE) (LATREILLE, 1806) SOB CONDIÇÕES LABORATORIAIS. Arquivo 
Brasileiro de Medicina Veterinária e Zootecnia, v. 52, n. 6, 2000.

http://www.ufpel.edu.br/cic/2008/cd/pages/pdf/CB/CB_00323.pdf, em 29/04/2012.

\section{CRUZ-VAZQUEZ AND Z. GARCIA-VAZQUEZ . Short Communication Seasonal} distribution of Rhipicephalus sanguineus ticks (Acari: Ixodidae) on dogs in an urban area of Morelos, Mexico. Experimental and Applied. Acaralogy, 23, 1999.

Filipe Dantas-Torres'; Luciana Aguiar Figueredo"; Sinval Pinto Brandão-Filho.

Rhipicephalus sanguineus (Acari: Ixodidae), o carrapato vermelho do cão, parasitando humanos no Brasil. Rev. Soc. Bras. Med. Trop. vol.39 no.1, 2006. FORTES, Elinor, 2004. PARASITOLOGIA VETERINÁRIA - 4ªㅡD. Editora Ícone.

SILVEIRA, J.A.G.; PASSOS, L.M.F.; RIBEIRO, M.F.B. Population dynamics of Rhipiceplhalus sanguinus (Latrielle, 1806) in Belo Horizonte, Minas Gerais state, Brazil. Veterinary Parasitology. Vol.161, n. 3-4, 2009.

OLIVEIRA, P.R. et al. Population dynamics of the free living stages of Amblyomma cajennense (Fabricius, 1787) (Acari: Ixodidae) on pastures of Pedro Leopoldo, Minas Gerais State, Brazil. Vet. Parasitol., 92: 295-301, 2000.

Rey, Luis. 2008. Parasitologia 4a. Ed. Editora: Guanabara Koogan, Rio de Janeiro.

Serra-Freire, N. M. \& R. P. Mello, 2006. Entomologia \& Acarologia na Medicina Veterinária. Rio de Janeiro, Editora L. F. Livros de Veterinária Ltda. 200p.

Sexton DJ, Burgdorfer W, Thomas L, Norment. BR 1976. Rocky Mountain spotted fever in Mississippi: survey for spotted fever antibodies in dogs and for spotted fever group rickettsiae in dog ticks. AM. J Epidemiol. 103: 192-197. 